\title{
A measure of limited joint motion and deformity correlates with HLA-DRB1 and DQB1 alleles in patients with rheumatoid arthritis
}

\author{
Ann Cranney, Rose Goldstein, Ba' Pham, Marianna M Newkirk, Jacob Karsh
}

\begin{abstract}
Objective-To assess factors associated with a poor outcome in rheumatoid arthritis (RA), a measure was developed of limited joint motion and deformity, a deformity index (DI), and correlated biochemical and genetic variables with the magnitude of the DI.

Methods-Forty patients were evaluated in a cross sectional study. Clinical measures included the DI and Health Assessment Questionnaire, and disease variables included the erythrocyte sedimentation rate, $C$ reactive protein, rheumatoid factor, and HLA-DRB1 and DQB1 alleles.

Results-Significant correlations were noted between increasing DI and duration of $R A$ and concentration of $C$ reactive protein. Patients with a DQB1*301 allele or DR4 allele had a higher DI than those without, and a positive trend was noted between increasing DI and dose of DRB1 RA susceptibility alleles. The trend was lost when a non-linear regression technique was used to remove the effect attributable to $\mathrm{C}$ reactive protein, suggesting an interrelation between persistent inflammation and genetics in determining total joint damage.

Conclusions-The DI may be useful to study interactions between genetic and inflammatory processes in rheumatoid disease progression.

(Ann Rheum Dis 1999;58:703-708)
\end{abstract}

Rheumatoid arthritis (RA) results often in irreversible damage of affected joints but disease outcome is not uniform. About $15-20 \%$ of patients have little deterioration after years of follow up. ${ }^{1-3}$ Unfortunately, most patients demonstrate substantial disease progression within a few years of onset whether assessed radiographically ${ }^{4-9}$ or by functional status. ${ }^{3} 1011$

Predicting outcome in patients with RA is difficult. To date, rheumatoid factor (RF) positivity and increases in the erythrocyte sedimentation rate (ESR) and $\mathrm{C}$ reactive protein (CRP) have been found to be the most consistent predictors of early radiographic and functional deterioration in several longitudinal studies of patients presenting with recent synovitis. ${ }^{12-20}$ Although ESR and CRP presumably reflect the same inflammatory process, they seem to exert additive effects on developing joint erosions. Possession of the "shared epitope" within the third hypervariable region of the HLA-DRB1 chain (amino acids 70-74: QKRAA/ QRRAA/ RRRAA) either on an HLA-DR4 (DRB1 ${ }^{\star} 04$ ) or non-DR4 allele has been associated with susceptibility to developing $\mathrm{RA}^{1421-29}$ and an additional effect of increasing gene dose and severity has been noted in most studies. ${ }^{232526}$ The combination of an HLA-DRB1 susceptibility allele and seropositivity has been found particularly predictive of development of joint erosions early in two studies. ${ }^{14} 27$

The measure that best describes outcome in $\mathrm{RA}$ is unsettled and has confounded the issue of identifying measures that may be associated with severity. In some publications, severity has been defined by the presence of extra-articular manifestations such as Felty's syndrome or vasculitis. ${ }^{28}$ Others report radiographic scales assessing articular narrowing and erosions, but limitations of radiographic scales in measuring total joint damage beyond 5-8 years of disease have been noted. ${ }^{8}{ }^{30}$ Pincus noted the inability of joint counts and other measures of clinical activity to predict irreversible damage, ${ }^{31}$ and has advocated the functional dimension of the Health Assessment Questionaire (HAQ) as the best measure of severity. ${ }^{32}$ The HAQ is an excellent predictor of work disability and mortality in RA, however in many patients, dysfunction measured by the HAQ is discrepant from damage measured by radiographs. ${ }^{33}$ Furthermore, the HAQ is not associated with HLA-DR4 genes, ${ }^{32}$ which are commonly associated with disease severity.

Scales of limited joint motion and deformity have been found to be the strongest correlate of radiographic scores in chronic $\mathrm{RA}^{31}$ and have been advocated as measures of total joint damage. ${ }^{31} 34$ Available scales include the Joint Alignment and Motion Scale (JAM), ${ }^{35}$ the Escola Paulista de Medicina-Range of Motion (EPM-ROM) scale, $^{36}$ and the scale of the American College of Rheumatology (ACR). ${ }^{37}$ We adapted the JAM and EPM-ROM to provide a measure of total joint damage, a deformity index (DI), and report our 
Deformity index

\begin{tabular}{|c|c|c|c|c|c|}
\hline & Normal $=0$ & Mild $=1$ & Moderate $=2$ & Severe $=3$ & $\begin{array}{l}\text { Total score } \\
\text { Right and } \\
\text { left }\end{array}$ \\
\hline \multicolumn{6}{|l|}{$\begin{array}{l}\text { Upper } \\
\text { extremity }\end{array}$} \\
\hline Shoulder & & $>120^{\circ}$ abduction & $90-120^{\circ}$ abduction & $<90^{\circ}$ abduction & \\
\hline Elbow & & $<25 \% \Downarrow \mathrm{ROM}$ & $\begin{array}{l}\text { Ligament instability, } \\
>25 \% \Downarrow \text { ROM }\end{array}$ & $\begin{array}{l}\text { Fusion, } \\
\text { dislocation }\end{array}$ & \\
\hline Wrist & & $\begin{array}{l}\text { Radial deviation } \\
<25^{\circ} \text {, } \\
<25 \% \Downarrow \text { ROM }\end{array}$ & $\begin{array}{l}\text { Radial deviation } \\
>25^{\circ},>25 \% \Downarrow \text { ROM, } \\
\text { volar subluxation }\end{array}$ & $\begin{array}{l}\text { Fusion, } \\
\text { dislocation }\end{array}$ & \\
\hline MCP & & $\begin{array}{l}\text { Ulnar deviation } \\
<25^{\circ}\end{array}$ & $\begin{array}{l}\text { Palmar subluxation, } \\
\text { ulnar deviation }>25^{\circ}\end{array}$ & $\begin{array}{l}\text { Dislocation } \\
\text { Fusion }\end{array}$ & \\
\hline Thumb IP & & $<25 \% \Downarrow$ flexion & $\begin{array}{l}\text { Instability, 25-75\% } \\
\Downarrow \text { flexion }\end{array}$ & $\begin{array}{l}\text { Fusion, } \\
\text { dislocation }\end{array}$ & \\
\hline PIP & & & $\begin{array}{l}\text { Swan neck or } \\
\text { Boutonniere's } \\
\text { deformity }\end{array}$ & Fusion & \\
\hline \multicolumn{6}{|l|}{$\begin{array}{l}\text { Lower } \\
\text { extremity }\end{array}$} \\
\hline Hip* & & & & Replacement & \\
\hline Knee & & $\begin{array}{l}\text { Valgus } 5-10^{\circ}, \\
\text { mild instability, } \\
25 \% \Downarrow \text { ROM }\end{array}$ & $\begin{array}{l}\text { Valgus } 10-15^{\circ} \\
\text { Moderate instability } \\
5-10^{\circ} \\
25-75 \% \Downarrow \text { ROM }\end{array}$ & $\begin{array}{l}\text { Valgus }>15^{\circ} \\
>75 \% \Downarrow \text { ROM }\end{array}$ & \\
\hline Ankle & & $<25 \% \Downarrow \mathrm{ROM}$ & $\begin{array}{l}\text { Subluxation, >25\% } \\
\Downarrow \text { ROM }\end{array}$ & $\begin{array}{l}\text { Dislocation } \\
\text { Fusion }\end{array}$ & \\
\hline Hindfoot & & Valgus $5-10^{\circ}$ & Valgus $10-20^{\circ}$ & Valgus $>20^{\circ}$ & \\
\hline MTP & & $\begin{array}{l}\text { Fibular deviation } \\
10-25^{\circ}\end{array}$ & $\begin{array}{l}\text { Fibular deviation } \\
>25^{\circ}\end{array}$ & $\begin{array}{l}\text { Fusion, } \\
\text { dislocation } \\
\text { (hammer toes) }\end{array}$ & \\
\hline
\end{tabular}

Normal range of motion (ROM) and alignment. Mild $-<25 \%$ decreased $\mathrm{ROM}<$ or mild malalignment. Moderate $26-75 \%$ decreased ROM or subluxation. Severe - fusion or dislocation. $\Downarrow=$ decrease.

*Fusion or replacement of any joint $=3$. Hips included in DI only if undergone joint replacement for RA.

Figure 1 The Deformity Index.

observations on relations between the magnitude of deformity in RA patients with longstanding disease and several biochemical, functional, and genetic measures.

\section{Methods}

Patients entering this cross sectional study were required to meet the 1987 ACR classification criteria for RA, having $>8$ years of disease, and having received $>1$ DMARD. The ESR was measured by the Westergren method and the $\mathrm{RF}$ and CRP were measured by nephelometric methods performed routinely in our hospital clinical laboratory. A value of $<35 \mathrm{KIU} / 1$ is reported for all sera considered to be seronegative, and RF concentrations in seropositive sera are reported as a continuous number starting from $35 \mathrm{KIU} / 1$. CRP is measured as a continuous number from 0 and values $>8 \mathrm{mg} / 1$ are considered increased. The ESR, RF, and CRP were measured only at study entry and that value used for all statistical evaluations.
For HLA class II typing, genomic DNA was extracted from peripheral blood by the DTAB/ CTAB method of Gustincich et al. ${ }^{38}$ The HLADRB1 alleles were amplified by a polymerase chain reaction (PCR) with a primer specific for polymorphisms of the first hypervariable region (HVR1). PCR products were hybridised to membrane bound sequence specific oligonucleotide probes (high resolution). After hybridisation, biotinylated hybrid molecules were identified by a colorimetric reaction using streptavidin-alkaline phosphatase conjugate (Cantype strips). Positive reactions were recorded and hybridisation patterns were translated into HLA-DRB1 genotypes using CANTYPE HLA DNA Analysis Software. HLADQB1 typing was performed using the Dynal DQB1-SSP set, which contains 5' and 3' primers for DQB1*0501-0504, 0601-0612, 02010203, 0301-0306, and 0401-0402 alleles.

Patients were classified into those without an HLA-DRB1 RA susceptibility epitope, those 
Table 1 Frequency of selected HLA class II alleles, RA susceptibility epitopes and associations with Deformity Index (DI), CRP, ESR and RF in 40 RA patients

\begin{tabular}{|c|c|c|c|c|c|c|}
\hline $\begin{array}{l}\text { HLA class II } \\
\text { allele }\end{array}$ & & $n(\%)$ & $\begin{array}{l}D I \\
\text { (mean (SD)) }\end{array}$ & $\begin{array}{l}C R P^{\star} \\
(m g / l)\end{array}$ & $\begin{array}{l}E S R^{\star} \\
(m m 1 s t h)\end{array}$ & $\begin{array}{l}R F^{\star} \\
(K I U / l)\end{array}$ \\
\hline \multirow[t]{2}{*}{$\mathrm{DR} 4$} & + & $31(78)$ & $14.7(11.4) \dagger$ & $15.7(22.7)$ & $22(26)$ & $227(483)$ \\
\hline & - & $9(22)$ & $5.4(4.5)$ & $4.2(2.5)$ & $15(10)$ & $187(200)$ \\
\hline \multirow[t]{2}{*}{$\mathrm{DQB} 1 \star 301$} & + & $21(53)$ & $17(12.6) \ddagger$ & $19.1(27)$ & $27.5(30.1)$ & $311(576)$ \\
\hline & - & 19 (48) & $7.7(5.7)$ & $6.8(5.6)$ & $13.5(10.8)$ & $116(152)$ \\
\hline \multirow[t]{2}{*}{$\mathrm{DQB} 1 \star 302$} & + & $22(55)$ & $13.7(11.5)$ & $13.7(18.7)$ & $26.6(11.4)$ & $230(453)$ \\
\hline & - & $18(45)$ & $11.7(10.5)$ & $12.8(22.8)$ & $15.5(32.2)$ & 209 (434) \\
\hline \multirow[t]{2}{*}{$\mathrm{DQB} 1{ }^{\star} 501$} & + & $11(28)$ & $11.9(11)$ & $8.8(10)$ & $17.3(9.5)$ & $130(134)$ \\
\hline & - & $29(73)$ & $12.8(11)$ & $15.1(23.6)$ & $21.6(26.8)$ & $255(510)$ \\
\hline \multicolumn{7}{|c|}{ Number of RA HLA-DRB1 susceptibility alleles } \\
\hline \multicolumn{2}{|c|}{0} & $6(15)$ & $6(5.5)$ & $5.5(2)$ & $12(9.8)$ & $263(220)$ \\
\hline \multicolumn{2}{|l|}{1} & $18(45)$ & $10.7(8.8)$ & $12(23.7)$ & $20.1(17.9)$ & $258(601)$ \\
\hline \multicolumn{2}{|l|}{2} & $16(40)$ & $17.3(12.8)$ & $17.4(20.1)$ & $24.4(31.7)$ & $157(213)$ \\
\hline
\end{tabular}

*38 patients had CRP, ESR and RF measured. $\nmid \mathrm{p}=0.01$ versus non-DR4 RA patients. $\neq \mathrm{p}=0.03$ versus non-DQB1*301 RA patients. Data shown as number (\%) and mean (SD).

with an epitope on an HLA-DR4 allele $\left(\mathrm{DRB} 1{ }^{\star} 0401,{ }^{\star} 0404,{ }^{\star} 0405,{ }^{\star} 0408,{ }^{\star} 0409\right.$, $\left.{ }^{\star} 0410,{ }^{\star} 0413,{ }^{\star} 0416,{ }^{\star} 0419,{ }^{\star} 0421\right)$ and those with an RA susceptibility epitope on a non-DR4 allele $\left(\mathrm{DRB}^{\star} 0101,{ }^{\star} 0102,{ }^{\star} 1001\right.$, $\left.{ }^{\star} 1402,{ }^{\star} 1406\right)$. The role of RA susceptibility gene dose was examined by classifying patients into 0,1 , and 2 epitope groups regardless of position on a DR4 or non-DR4 allele. The role of HLA-DQB1 alleles was examined by classifying patients into those without and with an HLA-DQB1 allele (DQB ${ }^{\star} 0301,{ }^{\star} 0302$, and $\left.{ }^{\star} 0501\right)$ linked to RA susceptibility HLA-DRB1 epitopes.

The DI (fig 1) assesses the joint areas in the JAM, but uses the 4 point scale of the EPM-ROM. Joints are scored based on the appearance of deformity and the range of assisted motion. Joint replacement or fusion surgery renders a score of 3 . Hips are included only if replaced for the destructive effects of RA.

Statistical assessments were performed by the Wilcoxon rank sum test and Spearman rank correlation. Levels of deformity across susceptibility epitope gene dose were compared using analysis of variance (ANOVA). We explored further the possible three way associations between deformity, ESR or CRP, and gene dose by spline regression. ${ }^{39}$ Spline regression is essentially a non-parametric method of trend analysis, and in our study of relations between multiple covariates and RA severity, it is used to assess the effects of a continuous confounder, CRP or ESR, on the apparent trend between gene dose and deformity. Particularly given our small sample size and probable non-logistic trends between variables, spline regression was optimal to explore these specific three way associations. ${ }^{40}{ }^{41}$

Analyses were performed in both Splus and SPSS statistical software packages. Correction of our $\mathrm{p}$ values for multiple comparisons was not performed because we conducted our study as an exploratory one and performed multiple statistical assessments. All statistically significant associations with the DI that we noted will need to be confirmed in larger studies and the data from this exploratory study allow the calculation of sample sizes to confirm the validity of the above observations.

\section{Results}

The patients, 13 men and 27 women, had a mean (SD) age of 58 (13) years (range 37-82) and mean (SD) duration of RA of 18 (9) years (range 8-40). The use of disease modifying anti-inflammatory dugs (DMARDs), past and present, ranged from 1-6. Twenty six patients $(65 \%)$ had started DMARD treatment within two years of disease onset. Fourteen patients (11 women and 3 men) were receiving prednisone at evaluation.

The mean (SD) DI was 12.5 (10.9) (range $0-44)$. There were no significant correlations between the DI and patient age, number of DMARDs used for treatment, or early $(<2$ years) versus later ( $>3$ years ) initiation of DMARD treatment. The DI did not differ between prednisone treated and untreated patients, did not correlate with the ESR or RF concentration, and did not differ between the 12 seronegative versus 26 seropositive patients.

As anticipated, there was a significant correlation between magnitude of DI and duration of RA ( $r=0.39, \mathrm{p}=0.013)$ over the 8 to 40 year range of disease duration. The DI correlated also with the magnitude of the CRP $(r=0.43$, $\mathrm{p}=0.007)$. The 24 patients with a normal CRP had a significantly lower DI $(9.4(7.6))$ than 14 patients with increased CRP (19.4 (13.1)) $(p=0.03)$.

Increasing DI was associated with increasing scores in the functional $(r=0.40, \mathrm{p}<0.013)$ and pain $(r=0.59, \mathrm{p}<0.001)$ dimensions of the HAQ. The HAQ correlated also with ESR $(r=0.50, \quad \mathrm{p}=0.001)$ and CRP $(r=0.56$, $\mathrm{p}<0.001)$, but not RF. The HAQ did not differ between DR4 positive and negative patients (1.29 (0.76) 0.93 (0.70), $\mathrm{p}=0.15)$.

There was a significant difference in DI between patients with an HLA-DR4 allele $(\mathrm{n}=31, \mathrm{DI}=14.5(11.4))$ and those without $(\mathrm{n}=9, \mathrm{DI}=5.4$ (4.5), $\mathrm{p}=0.01)$ (table 1). The most common DR4 susceptibility allele was $\mathrm{DRB}^{\star} 0401$ and those carrying an allele $(\mathrm{n}=22)$ had a significantly higher DI $(16.1(12.3))$ than those without $(\mathrm{n}=18,8.3(7.1), \mathrm{p}=0.03)$.

Six RA patients (15\%) were without a susceptibility epitope, and three $(8 \%)$ had a susceptibility epitope on a non-DR4 allele (two patients with $\mathrm{DRB}^{\star} 0101$ and one with $\left.\mathrm{DRB}^{\star} 1001\right)$.

The effect of gene dose on the DI was examined by categorising patients into those with 0 , 1 , and 2 susceptibility epitopes regardless of position on a DR4 or non-DR4 allele. There was a positive trend between increasing gene dose and a higher level of deformity (ANOVA, $\mathrm{p}=0.055$, table 1 ). The failure to reach statistical significance was attributed to the small sample size. The effect of gene dose on the DI was examined further using spline regression (fig 2). We displayed boxplots of the DI across gene dose, adjusted the effect of ESR or CRP on the DI, and displayed boxplots of the DI after the adjustment (that is, partial residuals after ESR or CRP) across gene dose. The positive trend for increasing gene dose and increasing DI was not affected by removing the influence of the ESR, noting that ESR and deformity did not correlate, but was changed 

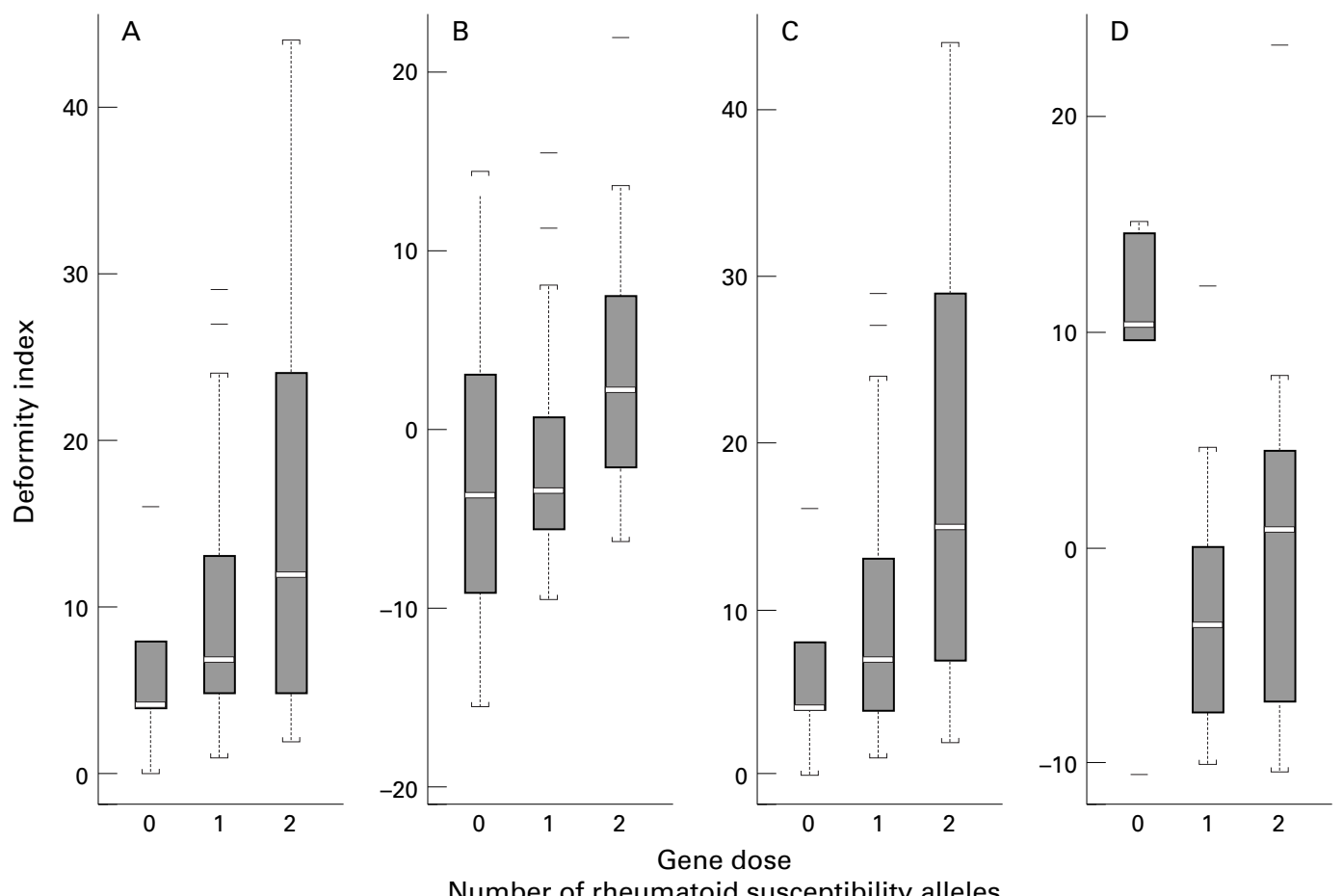

Number of rheumatoid susceptibility alleles

Figure 2 Relation between gene dose and the DI. The box plots demonstrate the median value (ight bar within shaded area) and variance (1st to $3 r$ quartiles in shaded area, $98 \%$ of values between enclosed bars, outliers indicated by single bars) of the DI ( $y$ axis) at the three gene doses (1,2, and 3 along $x$ axis) of DRB1 susceptibility alleles. Panels $A$ and $C$ are identical and display the distribution of deformities for patients who had measurements of ESR (panel A) or CRP (panel $C)$. There was a trend between increasing gene dose and increased DI $(p=0.055)$. We then used spline regression to adjust the effect of ESR or CRP on the DI, the partial residuals from the spline regression treated as adjusted deformity measures. Panels $B$ and $D$ display the partial residuals of deformity after adjusting for ESR or CRP respectively by gene dose. Adjusting for ESR (panel B) did not change the positive trend of increasing DI with increasing gene dose. Adjusting for CRP eliminated the trend (panel D), suggesting an interaction between the number of susceptibility alleles and CRP toward estimating deformity.

when the contribution of the CRP was removed, suggesting an interrelation between gene dose and CRP in determining the magnitude of the DI.

The DI did not differ between patients with and without a $\mathrm{DQB}^{\star} 0302$ or ${ }^{\star} 0501$ allele. However, 21 patients with a $\mathrm{DQB}^{\star} 0301$ allele had a significantly higher DI (17.1 (12.6)) than those without $(\mathrm{n}=19, \mathrm{DI}=7.7$ (5.7), $\mathrm{p}=0.03$ ). RF positivity was equivalent between $\mathrm{DQB}^{\star} 0301$ positive and negative patients, 16 of 20 versus 14 of 16 , as were concentrations of $\mathrm{RF}$ (nephelometry). The CRP was higher in $\mathrm{DQB}^{\star} 0301$ positive patients $(\mathrm{n}=20,19.1(27))$ versus negative patients $(n=18,6.8(5.6))$, but the difference was not statistically significant, $\mathrm{p}=0.43$ (table 1).

The HLA-DQB ${ }^{\star} 0301$ allele is linked to the RA HLA-DRB1 susceptibility alleles. In our study 15 of the 22 patients who were HLA-DRB ${ }^{\star} 0401$ positive were HLA$\mathrm{DQB}^{\star} 0301$ positive. As the increase in DI in association with the DQB and DRB alleles is similar, it is not possible to determine which of the associations is strongest or paramount.

\section{Discussion}

Our objectives were to establish a measure of total irreversible joint damage in RA and to assess the contributions of biochemical and genetic variables to the derivation of that outcome. In this cross sectional study, we approached the assessment of outcome in a retrospective manner by evaluating patients with longstanding disease treated at a single centre, reasoning that these patients, relatively homogeneous for therapeutic approaches would demonstrate the range of outcomes that they were destined to experience by virtue of their risk factors.

The rationale for developing an alternate measure of outcome is provided by the limitations of the currently used functional and radiographic scales. While each are excellent, they measure somewhat different aspects of outcome. Functional scales do not always measure joint damage. ${ }^{313}$ Radiography provides a direct measure of damage but assessment of the magnitude of joint damage by radiography has restrictions. The Steinbrocker scale $^{42}$ is only semi-quantitative. The quantitative methods of Larsen ${ }^{93}$ and Sharp ${ }^{44}$ even when modified to include the feet $^{45}{ }^{46}$ in addition to the joints of the hands and wrists, do not measure all joints. In addition, scores of joint damage seem to follow a non-linear time course. An apparent plateau is reached at about $5-8$ years of disease. ${ }^{830}$ This plateau reflects the inherent difficulty in scoring some joints as well as the finite nature of joint score scales. Damage that has occurred beyond the maximum score is unmeasured. While radiographic methods are excellent at measuring change during the initial years of disease, the plateau limits measuring total damage in patients with longstanding disease.

Scales of limited joint motion also measure RA severity and correlate with the HAQ and radiographic scores. ${ }^{31}{ }^{34}$ We adapted two previously reported scales of altered joint motion 
and deformity to create the DI. The DI has not been compared directly with its predecessors, makes no claims of superiority, and has not been formally validated for content and performance as a measuring instrument. However, its utility and reliability are supported by the statistically significant correlations with the functional and pain components of the HAQ, the duration of RA, the concentration of CRP, and HLA-DR and DQ alleles.

The strengths of our statistical associations are modest to moderate, and in a study of our relatively small sample size we are unable to establish a hierarchy of risk factors in determining damage. For example, RA is a progressive disease, and the association between disease duration and severity that we and others have noted may be the predominant determinant of deformity. Because our study was an exploratory evaluation, we did not take the severe step of correcting our $\mathrm{p}$ values for the multiple comparisons performed to eliminate the weaker associations. Still, correlations in the range of magnitudes of 0.4 to 0.5 as we have noted for duration of disease and CRP concentration means that each of these variables accounts only for less than $20 \%$ of the total variation in DI and suggests that multiple factors probably account for the total damage that has occurred over many years of disease. However, how these variables might interact to affect outcome is unknown.

Our CRP data agree with the results of other studies that found persistent CRP increases associated with progression of RA. ${ }^{15} 18 \mathrm{In}$ contrast with some ${ }^{13}$ but agreeing with other ${ }^{17}$ studies, we found no association between the ESR or seropositivity and severity of outcome. We measured ESR, CRP, and RF at a single point in time at a minimum of eight years from disease onset. Our data set does not contain serial measures of these parameters. Most probably, a more precise evaluation of the association of these parameters and severity of disease outcome could be derived from the correlation of the DI and an integrated measure (area under the curve) of serial evaluations of these parameters.

HLA-DRB1 alleles have usually been associated with disease severity ${ }^{21-25} 47$ and an effect of increasing gene dose is noted in most, ${ }^{25-27}$ but not all $^{21}{ }^{29}$ studies. We also found the DI significantly higher in HLA-DR4 positive patients, and noted a positive trend that we consider relevant albeit not statistically significant $(p=0.055)$ between HLA-DRB1 susceptibility epitope gene dose and the magnitude of the DI. Spline regression revealed an interaction between CRP and susceptibility alleles on the DI. This interaction between correlates of deformity, while not surprising, is important because this observation is one of the first to tackle a shortcoming of almost all genetic studies where there has been a general lack of analysis for confounding effects of other variables on disease progression. Our observation is similar to one made in a minocycline trial. In that study a positive correlation of gene dose and development of new erosions was noted among placebo treated patients. Minocycline treatment suppressed the development of erosions and among the treated patients the relation between gene dose and numbers of erosions was lost. ${ }^{26}$

We also noted a positive association between the $\mathrm{DQB}^{\star} 0301$ allele and RA severity. It must be noted that this HLA-DQB1 allele is linked to the RA susceptibility HLA-DRB1 epitopes. It is therefore not possible in this study to designate which of the HLA class II alleles is more strongly associated with deformity. In the literature, HLA-DQ alleles do not seem to code for susceptibility to RA and evidence for an effect on severity is contradictory (reviewed by Wagner et $a l^{27}$ ). The contradictory results centre on the method of measuring severity, be it the need to use DMARDs, in which a positive effect was noted, ${ }^{48}$ or the presence of extra-articular manifestations, ${ }^{28}$ or active joints ${ }^{27}$ where negative results were obtained. Thus, while we make no claim that measurement of DRQ alleles adds more information than measurement of DRB alleles in RA, our observation contributes insights into preferred measures of RA disease severity and proposes a disease model that may allow further exploration into a separate role of DQB alleles in RA.

The limitations of our study emphasise caution in interpreting the results. This is a cross sectional study of small sample size and the results may differ from the predictive value of a variable determined in a longitudinal study of an inception cohort of all patients with new disease. In addition, the content of DI requires formal validation. Nevertheless, our demonstrated associations of DRB1 and DQB1 allelles with severity, and the interaction of genes and CRP in determining severity, support the contention that the DI, and/or similar scales, are worthwhile developing and evaluating fully in patients with RA.

Funding: Supported by a grant from the Alpha Omicron Society. Dr Cranney was a joint MRC/Arthritis Society Research Fellow. Dr Goldstein was a Research Scholar and Dr Newkirk is a Research Scientist of the Arthritis Society of Canada.

1 Duthie JJR, Brown PE, Truelove LH, Baragar FD, Lawrie AJ. Course and prognosis in rheumatoid arthritis. Ann Rheum Dis 1964;23:193-202.

2 Sherrer YS, Bloch DA, Mitchell DM, Young DY, Fries JF. The development of disability in rheumatoid arthritis. Arthritis Rheum 1986;29:494-500

3 Pincus T, Callahan LF, Sale WG, Brooks AC, Payne LE, Vaughn WK. Severe functional declines, work disability, and increased mortality in seventy-five rheumatoid arthritis patients studied over nine years. Arthritis Rheum 1984;27: patients 72 .

4 Thould AK, Simon G. Assessment of radiological changes in the hands and feet in rheumatoid arthritis: their correlation with prognosis. Ann Rheum Dis 1966;25:220-8.

5 Brook A, Corbett $M$. Radiographic changes in early rheumatoid disease. Ann Rheum Dis 1977;36:71-3.

6 Scott DL, Coulton BL, Bacon PA, Popert AJ. Methods of $\mathrm{X}$-ray assessment in rheumatoid arthritis: A re-evaluation. Br J Rheumatol 1985;24:31-9.

7 Fuchs HA, Kaye JJ, Callahan LF, Nance EP, Pincus T. Evidence of significant radiographic damage in rheumatoid arthritis within the first two years of disease. J Rheumato 1989;16:585-91.

8 Fuchs HA, Pincus T. Radiographic damage in rheumatoid arthritis: description by non-linear models. J Rheumatol 1992;19:1655-8

9 Larsen A, Thoen J. Hand radiography of 200 patients with rheumatoid arthritis repeated after a interval of one year. Scand J Rheumatol 1987;16:395-401.

10 Wolfe F, Cathey MA. The assessment and prediction of functional disability in rheumatoid arthritis. J Rheumatol 1991;18:12981306. 
11 Pincus T, Wolfe F, Callahan LF. Updating a reassessment of traditional paradigms concerning rheumatoid arthritis. In Wolfe F, Pincus T, eds. Rheumatoid arthritis: pathogenesis, assessment, outcome, and treatment. New York: Marcel Dekker, 1994:1-74

12 Suarez-Almazor ME, Soskolne CL, Saunders D, Russell AS. Outcome in rheumatoid arthritis. A 1985 inception cohort study. J Rheumatol 1994;21:1438-46.

13 Brennan P, Harrison B, Barrett E, Chakravarty K, Scott D, Silman A, et al. A simple algorithm to predict the development of radiological erosions in patients with early rheumatoid arthritis:prospective cohort study. BMJ 1996; 313:471-6.

14 Gough A, Faint J, Salmon M, Hassel A, Wordsworth P, Pilling $\mathrm{D}$, et al. Genetic typing of patients with inflammatory arthritis at presentation can be used to predict outcome. arthritis at presentation can be use

15 Devlin J, Gough A, Huissoon A, Perkins P, Holder R, Reece $\mathrm{R}$, et al. The acute phase and function in early rheumatoid arthritis. C-reactive protein levels correlate with functiona outcome. J Rheumatol 1997;24:9-13.

16 van Leeuwen MA, van Rijswijk $M H$, Sliuter WJ, van Rie PLCM, Kuper IH, van de Putte LBA, et al. Individual relationship between progression of radiological damage and the acute phase response in early rheumatoid arthritis. Towards development of a decision support system. J Rheumatol 1997;24:20-7.

17 Coste J, Spira A, Clerc D, Paologgi J-B. Prediction of articular destruction in rheumatoid arthritis: Disease activity markers revisited. J Rheumatol 1997;24:28-34.

18 Munro R, Capell H. C-reactive protein levels correlate with functional outcome. J Rheumatol 1997;24:1852-3.

19 Otterness IG. The value of C-reactive protein measurement in rheumatoid arthritis. Semin Arthritis Rheum 1994;24: 91-104.

20 Hassell AB, Plant MJ, Clark S, Fisher J, Jones DW Saklatvala J, et al. Small joint synovitis in rheumatoid arthritis: Should it be assessed seperately? Br J Rheumato 1995;34:51-5.

21 Boki KA, Panayi GS, Vaughan RW, Drosos AA, Moutsopoulos HM, Lanchbury JS. HLA Class II sequence polymorphisms and susceptibility to rheumatoid arthritis in Greeks. Arthritis Rheum 1992;35:749-55.

22 Nepom GT, Nepom Nepom BS. Prediction of susceptibility to rheumatoid arthritis by human leukocyte antigen genotyping. Rheum Dis Clin North Am 1992;18:785-92.

23 Toda Y, Minamikawa Y, Akagi S, Sugano H, Mori Y, Nishimura $\mathrm{H}$, et al. Rheumatoid susceptibility alleles of Nishimura $\mathrm{H}$, et al. Rheumatoid susceptibility alleles of HLA-DRB1 are genetically recessive to non-suscceptible
alleles in the progression of bone destruction in the wrists alleles in the progression of bone destruction in the wrists
and fingers of patients with RA. Ann Rheum Dis 1994;53: 587-92

24 Jawaheer D, Thomson W, MacGregor AJ, Carthy D, Davidson J, Dyer PA, et al. "Homozygosity" for the HLA-DR shared epitope contributes the highest risk for rheumatoid arthritis concordance in identical twins. Arthritis Rheum 1994;37:681-6.

25 Weyand CM, McCarthy TG, Goronzy JJ. Correlation between disease phenotype and genetic heterogeneity in rheumatoid arthritis. J Clin Invest 1995;95:2120-6.

26 Reveille JD, Alarcon GS, Fowler SE, Pillemer SR, Neuner R, Clegg DO, et al. HLA-DRB1 genes and disease severity in rheumatoid arthritis. Arthritis Rheum 1996;39: 1802-7.

27 Wagner U, Kaltenhauser S, Sauer H, Arnold S, Seidel W, Hantzschel JR, et al. HLA markers and prediction of clinical course and outcome in rheumatoid arthritis. Arthritis Rheum 1997;40:341-51.

28 Perdriger A, Chales G, Semana G, Guggenbuhl P, Meyer O, Quillivic F, et al. Role of HLA-DR-DR associations in the expression of extraarticular manifestations and rheumatoid factor in rheumatoid arthritis. J Rheumatol 1997;24: $1272-6$
29 Suarez-Almazor ME, Tao S, Moustarah F, Russell AS, Maksymowych W. HLA-DR1, DR4, and DRB1 disease related subtypes in rheumatoid arthritis. Association and susceptibility but not severity in a city wide community based study. J Rheumatol 1995;22:2027-33.

30 Salaffi F, Ferracioli GF. Progress of the anatomical damage in rheumatoid hands. Radiography of the natural course of the disease or of the course during treatment? Scand J the disease or of the course

31 Pincus T, Larsen A, Brooks RH, Kaye J, Nance EP, Callahan LF. Comparison of 3 quantitative measures of hand radiographs in patients with rheumatoid arthritis: Steinbrocker Stage, Kaye modified Sharp score, and Larsen score. J Rheumatol 1997;24:2106-12.

32 Pincus T. Why should rheumatologists collect patient self-report questionnaires in routine rheumatologic care? Rheum Dis Clin North America 1995;21:271-319.

33 Griffiths B, Situnayake RD, Emery P. Altered damage/ function relationships in different racial groups with rheumatoid arthritis. [Abstract]. Arthritis Rheum 1997;40: S155.

34 Pincus T. Assessment of long term outcomes in rheumatoid arthritis. Rheum Dis Clin North Am 1995;21:619-54.

35 Spiegel TM, Spiegel JN, Paulus HE. The joint alignment and motion scale: A simple measure of joint deformity in patients with rheumatoid arthritis. J Rheumatol 1987;14: 887-92.

36 Ferraz MB, Oliviera LM, Araujo PMP, Atra E, Walter SD. EPM-ROM scale: an evaluative instrument to be used in rheumatoid arthritis trials. Clin Exp Rheumatol 1990;8: 491-4.

37 American Rheumatism Association. Dictionary of the rheumatic diseases. Vol I. New York: Contact Associates International, 1982:77.

38 Gustincich S, Manfiolett G, Del Sal G, Schneider C, Carninci P. A fast method for quality genomic DNA extraction from whole human blood. Biotechniques 1991;11:298302.

39 Myers RH. Classical and modern regression with applications. Boston: Duxbury Press, 1986

40 Greenland S. Dose-response and trend analysis in epidemiology: alternatives to categorical analysis. Epidemiology 1995;6:356-65.

41 Brenner $\mathrm{H}$, Blettner M. Controlling for continuous confounders in epidemiologic research. Epidemiology 1997;8:429-34

42 Steinbrocker O, Traeger CH, Batterman RC. Therapeutic criteria in rheumatoid arthritis. JAMA 1949;140:659-62.

43 Larsen A, Dale K, Eek M, Pahle J. Radiographic evaluation of rheumatoid arthritis by standard reference films. J Hand Surg 1983;8:667-9.

44 Sharp JT. Radiographic evaluation of the course of articular disease. Clin Rheum Dis 1983;9:541-7.

45 van der Heijde DMFM, van Riel PLCM, van Leeuwen MA van't Hof MA, van Rijswijk MH, van de Putte LBA. Prognostic factors for radiographic damage and physical disability in early rheumatoid arthritis. A prospective follow up study of 147 patients. Br J Rheumatol 1992;31:519-25.

46 van der Heidje DMFM, van't Hof MA, van Riel PLCM, van Leeuwen MA, van Rijswijk MH, van der Putte LBA. Validity of single variables and composite indices for measuring disease activity in rheumatoid arthritis. Ann Rheum Dis 1992;51:177-81

47 Weyand C, Xie C, Goronzy JJ. Homozygosity for the HLADRB1 alleles selects for extraarticular manifestations in rheumatoid arthritis. J Clin Invest 1992;89:2033-9.

48 Singal DP, Green D, Reid B, Gladman DD, Buchanan WW. HLA-D region genes and rheumatoid arthritis: importance of DR and DQ genes in conferring susceptibility to RA. Ann Rheum Dis 1992;51:23-8. 